\title{
Pyrolysis of copolymers based on alkyl methacrylates with $\mathrm{C}_{1}-\mathrm{C}_{8}$ alkyl chain
}

\author{
Zbigniew Czech*, Agnieszka Kowalczyk, Dominika Sowa \\ Institute of Organic Chemical Technology, West Pomeranian University of Technology, \\ ul. Pułaskiego 10, PL 70-322 Szczecin, Poland \\ *E-mail address: psa_czech@wp.pl
}

\begin{abstract}
The manuscript describes pyrolysis of copolymers based on selected alkyl methacrylates containing $\mathrm{C}_{1}-\mathrm{C}_{8}$ alkyl side chain at temperatures between $250{ }^{\circ} \mathrm{C}$ and $400{ }^{\circ} \mathrm{C}$ which was studied using pyrolysis-gas chromatography. The kind and composition of thermal degradation products gave practical information about the mechanism of pyrolysis of copolymers synthesized by using of typical commercially available alkyl methacrylates. It was observed that the main thermal degradation products from alkyl methacrylate copolymers are monomers, in this case alkyl methacrylates using by synthesis. Other pyrolysis by-products formed during thermal degradation were carbon dioxide, carbon monoxide, methane, ethane, methanol, ethanol and propanol-1.
\end{abstract}

Keywords: methacrylate copolymers; pyrolysis; methyl methacrylate; ethyl methacrylate; butyl methacrylate; 2-ethylhexyl methacrylate

\section{INTRODUCTION}

The special group of methacrylic resins, namely methacrylate copolymers with their excellent physical, chemical and mechanical properties are attractive and important specialty polymers. They are widely used in many applications such as raw materials for adhesives, polymeric films, plasticizers, paints varnishes and sealants in technical and medical areas. Polymers based on alkyl methacrylates are widely used as construct materials and coatings. Their properties depend particularly on the type of the length of alkyl group in side chain. Chain branching enhances hardness while elongation increases plasticization [1].

Pyrolysis gas chromatography (Py-GC) is a method, which easily, rapidly and inexpensively characterizes the polymer formulation as polymer or compounded polymeric material [2-3]. In properly chosen conditions this method allows to conduct transformation waste in to useful products. In case of polymer products, especially polyacrylates and polymethacrylates, it is possible to reproduce monomers, which build degradable polymers [4-6]. When using the pyrolysis coupled with gas chromatography also allows identifying investigated material, which has significant meaning in case of complaints. The special group of acrylic resins, namely poly(alkyl methacrylates) or alkyl methacrylate copolymers are attractive and important specialty polymers. They are very interesting for adhesive applications, characterized by excellent compatibility with acrylic and methacrylic polymers and with wide range of other polymers. They can be used especially for modification of aqueous acrylic and methacrylic dispersions. These polymers display several unique properties, such as extremely good weather and aging resistance, non yellowing properties, low permeability of oxygen, and good plasticizers resistance. Their major advantages are 
photostability and resistance to hydrolysis [7]. The thermal behavior of acrylic and methacrylic copolymers has been the target of some reports [8-10].

\section{EXPERIMENTAL}

\section{1. Materials}

Acrylic copolymers using alkyl methacrylates as monomers were synthesized in ethyl acetate at $77{ }^{\circ} \mathrm{C}$ by $50 \mathrm{wt} . \%$ of polymer content with $1 \mathrm{~h}$ monomers dosage time and $3 \mathrm{~h}$ postreaction. The synthesized copolymers containing $45 \mathrm{wt} \%$ of 2-ethylhexylmethacrylate (2EHMA), 25 wt. $\%$ of butyl methacrylate (BMA), 15 wt.\% of ethyl methacrylate (EMA) and 15 wt. $\%$ of methyl methacrylate (MMA) in presence of $0.1,0.2$ and 0.3 wt. $\%$ of radical thermal initiator 2,2'-azo-bis-diisobutyronitrile (AIBN) according to polymer content.

The different concentration of AIBN allows to variation of viscosity and molecular weight of synthesized copolymers. All raw materials were available from BASF (Germany).

The synthesized copolymers based on selected alkyl methacrylates with $C_{1}-C_{8}$ alkyl side chain were characterized by viscosities measured at room temperature using a viscosimeter Rheomat RM (Rheometric Scientific) with nr 3 spindle and by weight average molecular weights $\left(\bar{M}_{w}\right)$, number average molecular weights $\left(\bar{M}_{n}\right)$, and polydispersities $\left(P_{d}\right)$ (Tab. 1).

Molecular weight was determined with the use of liquid chromatography LaChrom: RI Detector Li-7490 and LaChrom UV Detector L-7400 Merck Hitachi supplied with PLgel $10^{6}$ Helwett-Packard column.

Table 1. Molecular weights $M_{W}$ and $M_{n}$ and polydispersity of synthesized copolymer containing selected alkyl methacrylates

\begin{tabular}{ccccc}
\hline $\begin{array}{c}\text { AIBN } \\
\text { [wt.\%] }\end{array}$ & $\begin{array}{c}\text { Viscosity } \\
{[\mathrm{Pa} \cdot \mathrm{s}]}\end{array}$ & $\begin{array}{c}\overline{\mathrm{M}}_{\mathrm{w}} \\
{[\text { Dalton }]}\end{array}$ & $\begin{array}{c}\overline{\mathrm{M}}_{\mathrm{n}} \\
{[\text { Dalton] }}\end{array}$ & $\mathrm{P}_{\mathrm{d}}=\frac{\overline{\mathrm{M}}_{\mathrm{w}}}{\overline{\mathrm{M}}_{\mathrm{n}}}$ \\
\hline 0.1 & 11.8 & 710000 & 244000 & 2.91 \\
0.2 & 9.3 & 602000 & 184000 & 3.27 \\
0.3 & 5.4 & 443000 & 118000 & 3.75 \\
\hline
\end{tabular}

The synthesized solvent-borne copolymers were dried $10 \mathrm{~min}$ at $110{ }^{\circ} \mathrm{C}$ in drying canal and after drying as dry solvent-free polymer films tested on thermal stability and on pyrolysis behavior.

The formed pyrolysis-products were evaluated using gas chromatography.

\section{2. Thermal stability}

Copolymer stability was assessed by thermogravimetry (TG) using model 2950 TGA unit interfaced with the TA Instruments Thermal Analyst 2100 control unit from TA Instruments Inc. The sample about $5 \mathrm{mg}$ was contained in a platinum sample pan and the TG 
cell was swept with nitrogen at $50 \mathrm{ml} / \mathrm{min}$ during degradation runs. The temperature was ramped at $5{ }^{\circ} \mathrm{C} / \mathrm{min}$ in the area between 200 and $400{ }^{\circ} \mathrm{C}$.

\section{3. Degradation process}

The quantitative and qualitative analyses were conducted by using of the following gas chromatography methods:

The determination of liquid products were conducted with an external standard method and following analytical conditions: gas chromatograph ThermoScientific GC $8000^{\text {Top }}$, capillary column-RESTEK RTX-5 $30 \mathrm{~m}$ x $0.53 \mathrm{~mm}, 1.5 \mu \mathrm{m}$ film, carrier gas-He $5 \mathrm{~cm}^{3} / \mathrm{min}$, detector temperature (FID) $-300{ }^{\circ} \mathrm{C}$, injector temperature $-280{ }^{\circ} \mathrm{C}$ (split 1:2), oventemperature program $-45^{\circ} \mathrm{C}(4 \mathrm{~min})$ to $420^{\circ} \mathrm{C}$ at $10^{\circ} \mathrm{C} / \mathrm{min}$.

The determination of gaseous products were conducted with an external standard method and following analytical conditions: gas chromatograph ThermoScientific TraceUltra micropacked column-ShinCarbon ST 100/120, $1 \mathrm{~m}, 0.95 \mathrm{~mm}$, carrier gas-He $8 \mathrm{~cm}^{3} / \mathrm{min}$, detector temperature (TCD) $-200{ }^{\circ} \mathrm{C}$, injector temperature $-100{ }^{\circ} \mathrm{C}$, oven-temperature program $-45^{\circ} \mathrm{C}(10 \mathrm{~min})$ to $250 \mathrm{C}$ at $10^{\circ} \mathrm{C} / \mathrm{min}$.

\section{RESULTS AND DISCUSSION}

The stability of the synthesized copolymer was determinate by thermogravimetry. Fig. 1 illustrates a comparison of the thermal degradation characteristics of synthesized copolymers with different molecular weights.

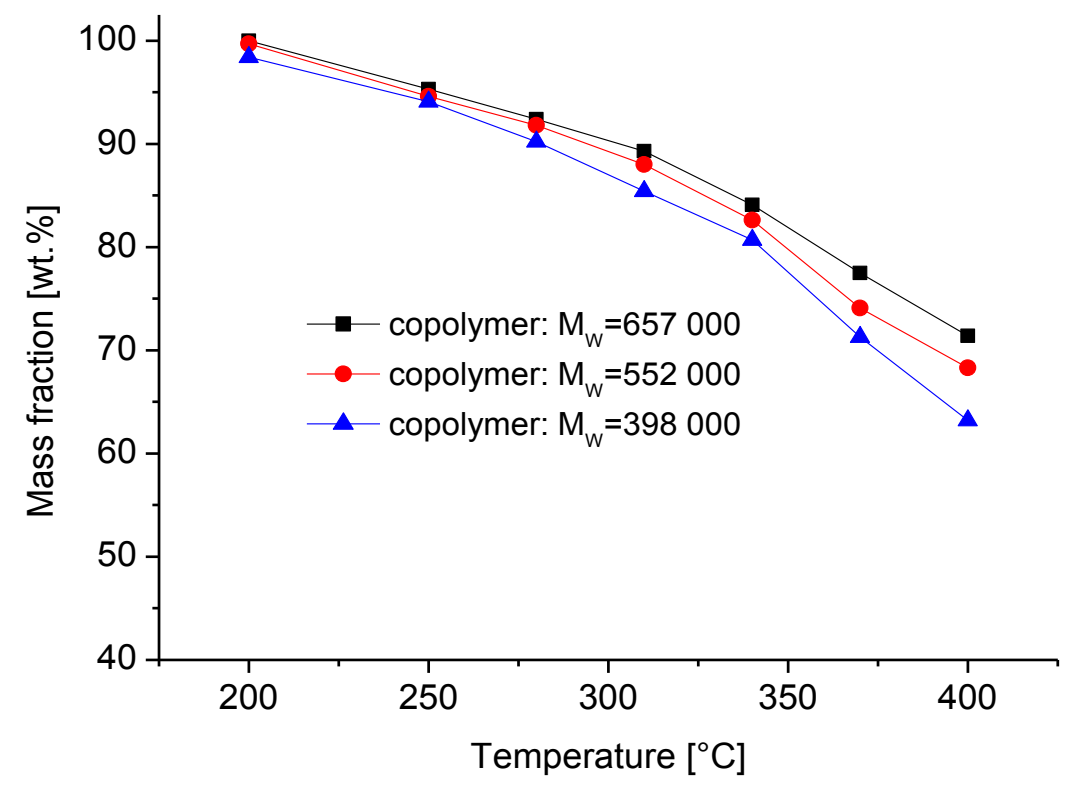

Fig. 1. Thermal stability of acrylic copolymers as a function of their molecular weight $\mathrm{M}_{\mathrm{W}}$.

As can readily be seen, the rate of initiation of degradation is much greater for the acrylic copolymers synthesized from 2-ethylhexyl methacrylate, butyl methacrylate, ethyl methacrylate and methyl methacrylate with greater molecular weight than for copolymers with lower molecular weight (Fig. 1).

The synthesis of copolymers based on selected alkyl methacrylates in presence of 0.1 , 0.2 and 0.3 wt.\% of radical thermal initiator AIBN allows to variation of viscosity and 
molecular weight of synthesized copolymers. The influence of AIBN amount on the molecular weight of synthesized solvent-borne methacrylic copolymers is illustrated in Table 1. The relatively high concentration of AIBN contributes to a greater possibility of free radical transfer during polymerization reaction by which de facto the molecular weights $\bar{M}_{w}$ and $\bar{M}_{n}$ of solvent-borne methacrylic copolymers decreases.

The thermal degradation products from copolymer containing in the polymer structure segments of 2-ethylhexyl methacrylate (2-EHMA), butyl methacrylate (BMA), ethyl methacrylate (EMA) and methyl methacrylate (MMA) in temperatures between $250{ }^{\circ} \mathrm{C}$ and $400{ }^{\circ} \mathrm{C}$ are summarized in Table 2, which also shows the concentration of the breakdown products as a function of temperature range.

The thermal degradation investigations were performed for acrylic copolymer with highest molecular weight $\overline{\mathrm{M}}_{\mathrm{w}}$ of 710000 . At lower temperatures, the polymers degrade nearly completely to the monomers alkyl methacrylates, alcohols and gases, and carbon dioxide, carbon monoxide, methane and later ethane appear only in small quantities. At higher temperatures, the copolymer concentration based on alkyl methacrylates decreases slowly, while the gas component content simultaneously increases.

Table 2. Composition of breakdown products during thermal degradation of acrylic copolymer.

\begin{tabular}{lcccccc}
\hline Pyrolysis products & \multicolumn{7}{c}{ Pyrolysis temperature [ $\left.{ }^{\circ} \mathrm{C}\right]$} \\
\hline & 250 & 280 & 310 & 340 & 370 & 400 \\
\hline & \multicolumn{7}{c}{ Concentration of breakdown products [wt.\%] } \\
\hline Methyl methacrylate & 99.8 & 99.7 & 99.6 & 98.1 & 97.4 & 96.6 \\
Ethyl methacrylate & 99.6 & 99.2 & 98.3 & 97.0 & 95.3 & 94.1 \\
Butyl methacrylate & 99.1 & 98.2 & 97.2 & 95.9 & 94.1 & 92.0 \\
2-Ethylhexyl methacrylate & 96.8 & 95.3 & 94.2 & 93.1 & 90.7 & 88.7 \\
Carbon monoxide & - & 0.2 & 0.7 & 0.9 & 1.2 & 1.6 \\
Carbon dioxide & - & 0.2 & 0.6 & 0.8 & 1.0 & 1.2 \\
Methane & - & - & 0.1 & 0.3 & 0.5 & 0.8 \\
Ethane & - & - & 0.1 & 0.1 & 0.1 & 0.1 \\
Methanol & - & - & 0.1 & 0.1 & 0.1 & 0.1 \\
Ethanol & - & 0.1 & 0.5 & 0.8 & 1.2 & 1.7 \\
Propanol & - & 0.1 & 0.2 & 0.5 & 0.9 & 1.4 \\
& & & & & &
\end{tabular}

It is illustrates in Table 2 , between $250{ }^{\circ} \mathrm{C}$ and $400{ }^{\circ} \mathrm{C}$ the concentration of methacrylate monomers drops from $99.8 \mathrm{wt} \%$ to $96.6 \mathrm{wt} \%$ for methyl methacrylate, from 99.6 wt. $\%$ to $94.1 \mathrm{wt}$ \% for ethyl acrylate, from $99.1 \mathrm{wt} \%$ to $92.0 \mathrm{wt}$. \% for butyl methacrylate and from $96.8 \mathrm{wt}$ \% to $88.7 \mathrm{wt}$. \% for 2-ethylhexyl methacrylate in thermal degradation by-products. The concentration of gases and alcohols is very low and continuous increase from $0.6 \mathrm{wt} . \%$ at $250{ }^{\circ} \mathrm{C}$ to $6.9 \mathrm{wt} . \%$ at $400{ }^{\circ} \mathrm{C}$. The concentration of thermal degradation products as a function of pyrolysis time are presented in Fig. 2. 


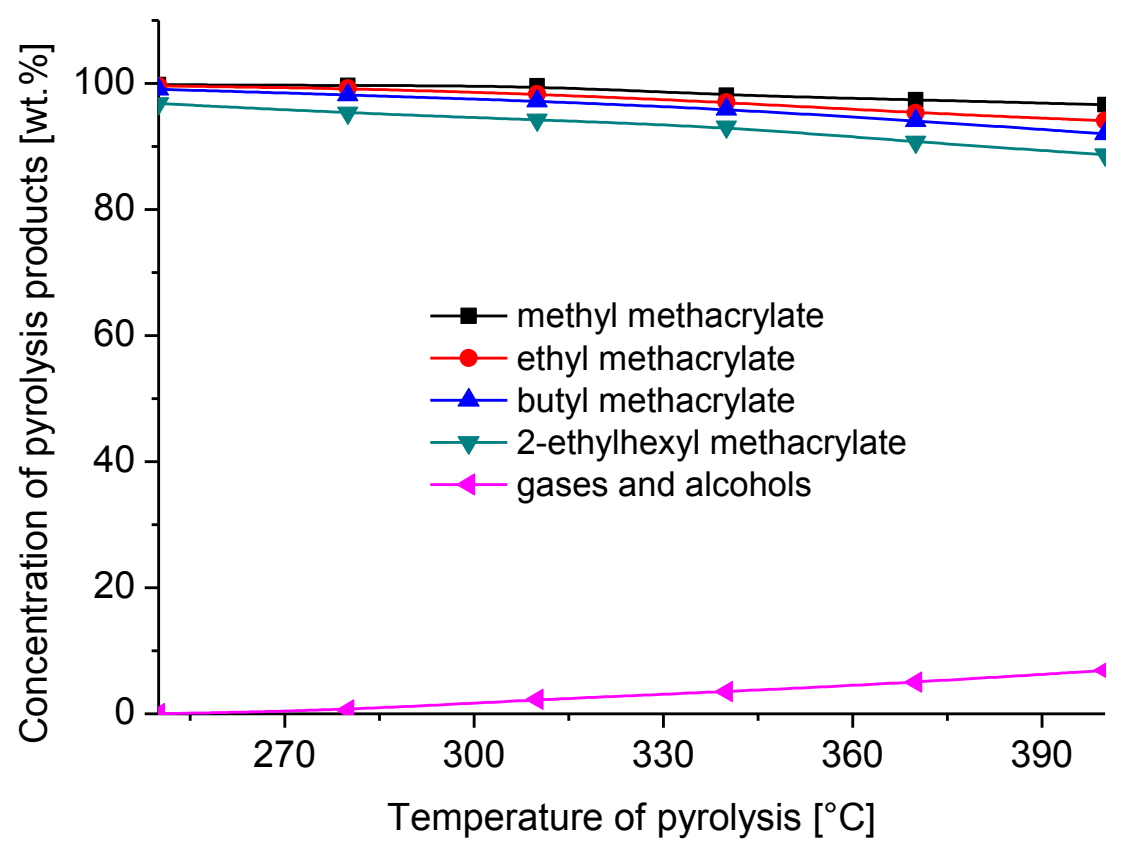

Fig. 2. Pyrolysis products during the pyrolysis of acrylic copolymer based on selected methyl methacrylates.

The major gaseous products are carbon monoxide, carbon dioxide, methane and ethane. A small concentration of alcohols like methanol, ethanol and propanol-1 was observed too. It was confirmed for each copolymers based on tested alkyl methacrylates that the corresponding methacrylate, such as methyl methacrylate, ethyl methacrylate, butyl methacrylate and 2-ethylhexyl methacrylate are the genuine thermal degradation products and they were only present in investigated pyrolysates. In discussing the thermal degradation process of acrylic copolymers based on alkyl methacrylates, it should be emphasized that it is a depolymerization process. The process of diffusion of degradation products throughout the acrylic polymers also plays an important role. The most important of these factors are the degradations conditions, especially the temperature of pyrolysis. It was been not observed the formation of typical breakdown products typically for poly(alkyl acrylates), such as alkenes, long chain alcohols and acrylate monomers.

The general thermal degradation mechanism of acrylic copolymers based on alkyl methacrylates includes random main-chain scission and side-chain reactions. As results of random main-chain scission monomer are formed according scheme in Fig. 3.

The principal degradation products of poly(alkyl methacrylates) are accordingly monomers used in polymerization process, and in the temperature range of interest the amount of the monomer formed (only methacrylates) according to process (1) is very dependent upon the pyrolysis temperature. The formation of energetically less favorable primary carbon radicals leads to methacrylate evolution. 


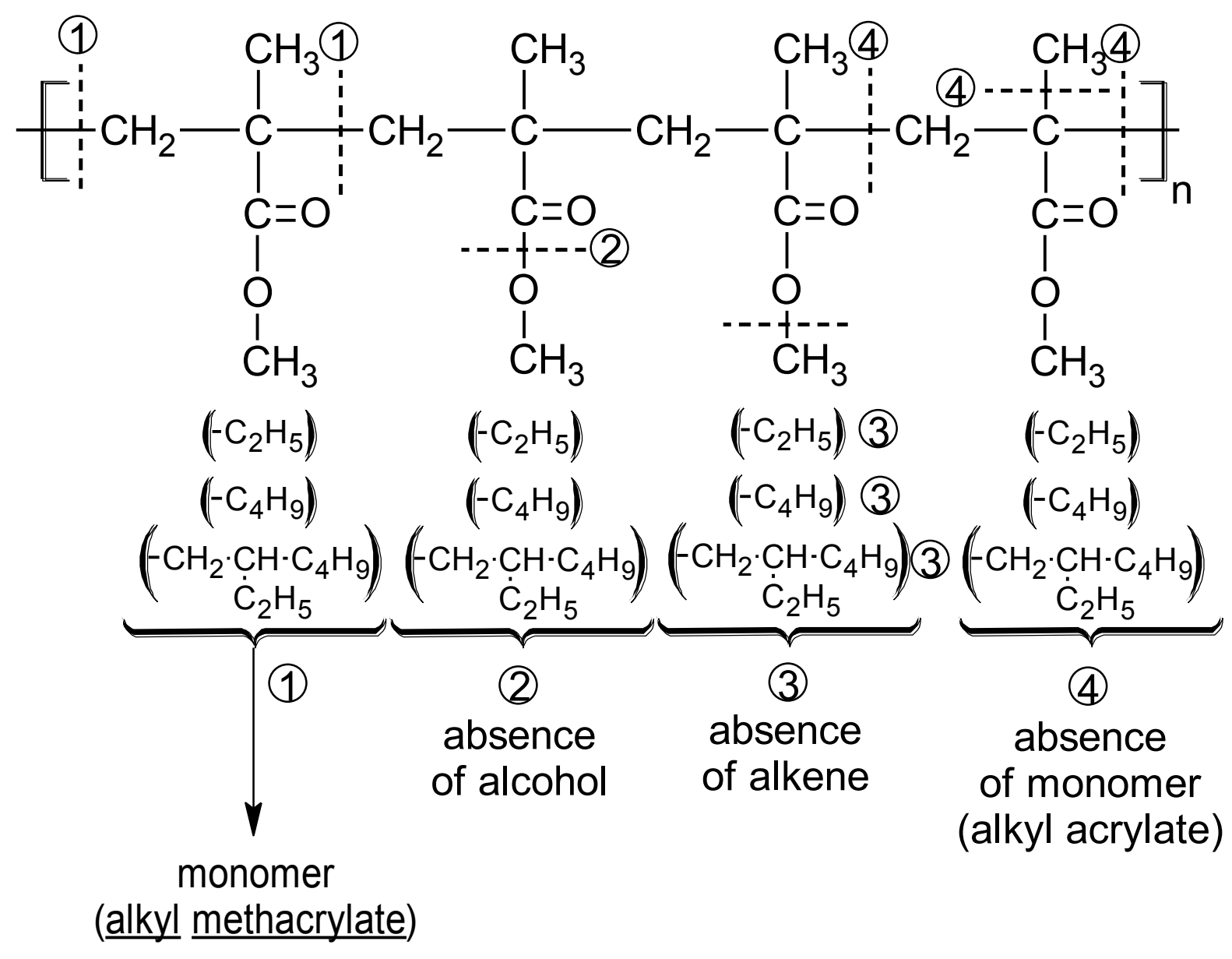

Fig. 3. Thermal degradation mechanism of poly(alkyl methacrylates)

From the quantitative results, it is possible to observe the effect of monomer yields, depending on the number of carbon atom in the alkyl side chain. The concentrations of monomers for short alkyl side chain (methyl, ethyl) were higher than for monomers from long side chain (butyl, 2-ethylhexyl). The longer alkyl side chain in the poly(alkyl methacrylates) the less monomers were formed during the pyrolysis. This mechanism of thermal degradation presented in Figure 8 supports the absence of alkenes, accordingly alcohols and monomers alkyl acrylates, what excludes the pyrolysis mechanisms (2), (3) and (4). During cracking reactions, especially at higher temperatures, are formed gases products and mixture of low molecular alcohols.

\section{CONCLUSIONS}

This work gives the full all-round results of thermal degradation of poly(alkyl methacrylates) in the wide range of high temperatures and suggest simple degradation mechanism providing a satisfactory explanation for the formation of major destruction products, namely accordingly alkyl methacrylates, such as metyl methacrylate, ethyl methacrylate, butyl methacrylate and 2-ethylhexyl methacrylate. The general mechanism of poly(alkyl methacrylates) thermal degradation includes random main-chain scission reactions.

Poly(alkyl methacrylates) produce monomers as the predominant degradation products in all investigated pyrolysis condition between $250{ }^{\circ} \mathrm{C}$ and $400{ }^{\circ} \mathrm{C}$. This process can be 
excellent applied for material recycling of methacrylic polymers waste for recovery of methacrylate monomers.

\section{REFERENCES}

[1] Z. Czech, Crosslinking of Pressure-Sensitive Adhesives Based on Acrylics, Szczecin University of Technology, Szczecin 1999.

[2] F. Wang, A. Burleson, J. Chromatogr. A. 833 (1999) 111-119.

[3] B. A. Howell, D. A. Spears, P. B. Smith, J. Therm Anal. Cal. 85 (2006) 115-117.

[4] Z. Czech, R. Pełech, Prog. Org. Coat. 65 (2009) 84-87.

[5] Z. Czech, R. Pełech, J. Therm. Ana.l Cal. 96 (2009) 83-86.

[6] Z. Czech, R. Pełech, Mater. Sci. Poland. 2 (2009) 851-856.

[7] L. Germinario, P. Shang, J. Therm. Anal. Cal. 1 (2008) 207-211.

[8] I. C. McNeil, S. M. Sadeghi, Polym. Degrad. Stabil. 30 (1990) 213-230.

[9] S. Tsuge, H. Ohtani, C. Vatanabe, Pyrolysis-GC/MS Data Book of Synthetic Polymers, Elsevier (2011).

[10] S. Yamaguchi, J. Hirano, Y. Isoda, Polym. J. 17 (1985) 1105-1116. 